PACS 81.40.-Z

\title{
Principles of processing of an ultrafine-grained structure in large -section billets
}

\author{
R. M. Imayev ${ }^{\dagger}$, A. A. Nazarov, R. R. Mulyukov, G. F. Khasanova, \\ R. M. Galeyev, O. R. Valiakhmetov \\ ${ }^{\dagger}$ renat_imayev@mail.ru
}

Institute for Metals Superplasticity Problems, RAS, 39 Khalturin St., 450001, Ufa, Russia

\begin{abstract}
Summarizing the results of the studies performed at IMSP RAS, the principles of processing of a uniform ultrafine-grained (UFG) structure in large-section billets by means of the technique of multiple isothermal forging are formulated. These principles imply a uniform introduction of plastic strain energy into large-section billets, minimization of contact friction between the die-set and the billets, and deformation processing in the temperature and strain-rate conditions that are most favourable for the development of dynamic recrystallization.
\end{abstract}

Keywords: multiple isothermal forging, severe plastic deformation, ultrafine grained and nanostructured materials, dynamic recrystallization, grain refinement.

\section{Introduction}

The scientific and applied tasks related to the processing of metals and alloys aimed at grain refinement have always been at the center of attention of researchers specializing in materials science and metal forming. The topicality of this field of studies increased drastically at the end of the 1980 's, when it became clear that the temperature of primary recrystallization in materials can be significantly decreased owing to large plastic strains attained, for instance, by the technique of torsion under high quasi-hydrostatic pressure [1]. Moreover, in materials with a relatively low melting temperature, such as nickel or copper, primary recrystallization can develop even at room temperature [2]. In this case, due to a low homologous temperature, the size of recrystallized grains can be as small as $d<100 \mathrm{~nm}$, i.e. a nanosized microstructure can be formed. This result led to the development of new metal processing techniques collectively termed severe plastic deformation (SPD) techniques, aimed at grain refinement. Among these techniques, equal-channel angular pressing (ECAP) has become the most widespread [3-5].

Let us consider the principles underlying SPD techniques $[4,5]$. The most important principle concerns the deformation temperature, which must be rather low $\left(T<0.4 T_{\mathrm{m}}\right.$, where $T_{\mathrm{m}}$ is the melting temperature of a material). It is at such temperatures that accumulation of dislocations to densities of $\rho>10^{14} \mathrm{~m}^{-2}$ required for the formation of a UFG structure becomes possible. At higher temperatures, due to recovery processes, the accumulated dislocation density turns out to be lower that leads to an increase in the size of recrystallized grains $d$ up to values exceeding $1 \mu \mathrm{m}$. The second principle stipulates an introduction of exceptionally high strain energy into the material so the true strain must exceed the values of $e \approx 6-8$. Here, it is noted that the accumulation of the required dislocation density $\rho>10^{14} \mathrm{~m}^{-2}$ occurs already after a strain of $e=0.5$ is attained. But to form a UFG structure with predominantly high-angle grain boundaries, a significantly higher strain is required. An essential condition for SPD is also the application of a high hydrostatic pressure $p$ which must exceed $1 \mathrm{GPa}$. The fulfillment of this condition, which is the third principle of SPD, ensures high deformability of materials, activates dislocation generation, decreases the rates of atom diffusion and recovery process. The fourth principle demands a non-monotonous development of deformation, which takes place, for instance, during ECAP processing via route $B_{C}$. The fifth principle speaks about the dependence of grain size on stacking fault energy and antiphase boundary energy (in the case of an ordered alloy).

The first three principles suggest that an experimenter has unlimited energy at his disposal that he can introduce into the material in the form of plastic strain energy and spend to overcome the contact friction, as well as an ideal, non-wearable tooling that withstands a considerable contact friction. In practice, fulfillment of the first principle comes down to conducting deformation processing preferably at room temperature or at the minimum temperature, at which a sample can be processed using this SPD procedure. Temperature, as one of the main factors influencing the structure formation, is not considered here. The fourth principle, as envisioned by the authors, should ensure a uniform development of deformation in a material. In this case, solely processing by ECAP via route $\mathrm{B}_{\mathrm{C}}$ is assumed. The fifth principle, in essence, is not a principle, since the grain size depends to the first place on the temperature and strainrate conditions of deformation. Since deformation processing 
is conducted at room temperature, homologous deformation temperatures will be different for materials with different stacking fault energies and antiphase boundary energies, which in reality accounts for the difference in grain sizes produced in various materials.

Analysis of the considered principles demonstrates that following the first and the third principles, the experimenter, to a great extent, works against the final goal, i.e. the formation of a UFG structure. Indeed, deformation at low temperatures, when thermally activated processes are impeded, proceeds in a rather localized manner. Even in such small samples that are subjected to torsion under high quasi-hydrostatic pressure, a non-uniform layered structure is observed, where layers with a recrystallized structure alternate with layers having a cellular fragmented structure [5]. In the conditions of quasi-hydrostatic pressure, recrystallization processes occur extremely slowly, as is the case, for instance, with stagnant zones of samples deformed by compression. From the stance of a conventional manufacturer, the first three principles will be unacceptable for him, since they do not correspond to the manufacturing realia demanding strict saving of power and materials.

As regards the fourth principle, it is also unsatisfactory from the point of view of producing a uniform UFG structure. Since ECAP processing is normally carried out at low temperatures, each emerging substructure is the material's response to a specific monotonous loading; a change in the deformation path tends to destruct the old substructure and create a new one typical for the new conditions [6]. Consequently, when routes with rotations are employed, a partial destruction of boundaries that formed earlier takes place, and the accumulation of misorientations proceeds slower than in the case of monotonous deformation. Therefore, routes $\mathrm{B}_{\mathrm{A}}$ and $\mathrm{B}_{\mathrm{C}}$ of ECAP processing usually lead to the formation of a mixed UFG structure with a high fraction of low-angle boundaries [7].

From the point of view of a manufacturer, a technique for producing a UFG structure can have a market potential if it provides a minimization of the introduced strain energy and energy consumption due to contact friction per weight unit of an UFG product. Another important point is that the technique must ensure the formation of a uniform, equiaxed UFG structure with a high fraction of high-angle grain boundaries possessing no sharp texture in large-section billets. Note should be made that the term «bulk» UFG materials is intentionally avoided here, since recently samples even in the form of films with a small thickness have been considered as bulk ones.

One of such techniques is multiple isothermal forging. Comparison of this technique with other cyclic techniques, which also allow one to preserve or restore the original threedimensional billet shape during deformation processing regardless of the strain, such as equal-channel angular pressing, twist extrusion etc., shows that the maximum strain $e_{\max }$ that a material can be subjected to while applying these techniques depends on the value of contact friction between the deformation tool and the billet, and the value of tensile stress emerging in the process.

In cyclic techniques of deformation processing of materials based on pressing or extrusion, considerable contact friction is the cause of faster fracture of samples (in case fracture of the deformation tool does not occur earlier). For instance, as reported in the paper [6], during pressing and extrusion of copper the value of $e_{\max }$ amounts 29 and 14, respectively. From all the above mentioned processes, only multiple isothermal forging allows avoiding considerable contact friction and, as a consequence, considerable tensile stress on the lateral surface, which can lead to a formation of cracks. Due to that, as was demonstrated in the paper [6] on the example of copper, a material can be subjected to fairly large plastic strains $(e=50)$ at room temperature without causing fracture of either the samples or the deformation tool.

In the present paper, the principles of producing a uniform UFG structure in large-section billets through the application of multiple isothermal forging are considered.

\section{The main idea of the technique}

The main idea of the technique of multiple isothermal forging is to make the fullest use of the potential of dynamic recrystallization and other thermally activated processes for grain refinement of metals and alloys. In other words, this technique is based on the use of the relation between the size of recrystallized grains and the conditions of isothermal deformation (temperature and strain rate): $d=d(T, \dot{\varepsilon})$. To implement the technique, it is necessary to solve the following two main tasks:

i) to produce in large-section billets a uniform, equiaxed fine-grained structure with a large fraction of high-angle grain boundaries having no sharp crystallographic texture; scale.

ii) to reduce stepwise the grain size down to the UFG

Solution of the first task is based on the use of the multiple forging scheme, which ensures uniform introduction into large-section billets of plastic strain energy and minimization of contact friction between the billets and the tooling. In the general case, this process is preceded by two preparation steps. First, alloys in the cast condition are usually characterized by a rather coarse-grained or coarse-lamellar structure. Therefore, it is reasonable to subject them, already at the stage of metallurgical production, to preliminary deformation processing (forging, extrusion, pressing, rolling, etc.) with a view to refine the initial cast structure. In the cases when the alloys have been modified and are characterized by a relatively small size of grain/colonies, it is possible to move immediately to the next step, which comprises preliminary investigations using model samples, to identify the temperature and strain-rate deformation conditions, most favourable for development of dynamic recrystallization. The model samples of a cylindrical shape are deformed by compression in various temperature and strain-rate conditions, and during this process the deformation behaviour of the material and the microstructure evolution are investigated. As a result of these studies, the fundamental relationship between the deformation mechanisms and the mechanisms and kinetics of dynamic recrystallization in a broad range of temperatures and strain rates of deformation processing is established, and the influence of the initial microstructure, dispersion degree and phase morphology on this triad is defined. Finally, 
after defining the temperature and strain-rate deformation conditions, optimal for development of recrystallizaton, on model samples, the process of producing a uniform, equiaxed fine-grained structure with a large fraction of high-angle grain boundaries, not having a sharp crystallographic texture, can be realized on large-section billets.

\section{The deformation scheme ensuring the most uniform dynamic recrystallization in large-section billets}

For a uniform introduction of plastic strain energy into large-section billets, it is reasonable to use the multiple isothermal forging scheme, which allows one to suppress strain localization in the material volumes with an already recrystallized microstructure (Fig.1). This scheme represents

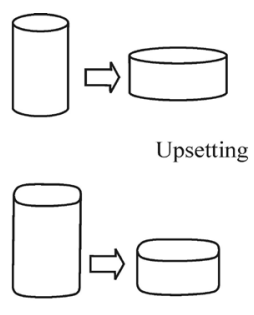

Turning by $90^{\circ}+$ upsetting

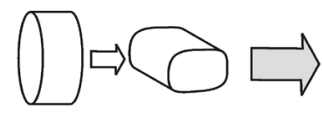

Turning by $90^{\circ}+$ upsetting
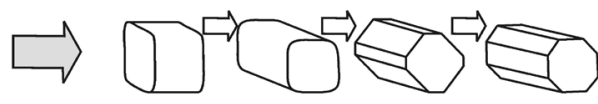

Drawing
Fig. 1. Principal scheme of multiple isothermal forging.

a cycle of operations including upsetting, turning and drawing, as a result of which, at the end of the cycle, the billet assumes approximately the same shape and dimensions as its original ones. Thus, the scheme ensures the cyclicity of deformation processing. Due to a non-uniform distribution of the strain rate field in the billet volume during multiple isothermal forging, at each pass with a change of the strain axis, new non-recrystallized volumes are deformed, as a result of which the microstructure of practically any bulk billet can be fully recrystallized. The strain degree $\varepsilon$ is selected at each pass in such a manner, on the one hand, as to ensure development of dynamic recrystallization $\left(\varepsilon>\varepsilon_{c r}\right)$, and on the other hand, as to avoid considerable contact friction and preserve mechanical stability at the next pass. Owing to cyclicity, the described scheme can be reproduced repeatedly, to fully work through the stagnant zones and attain the necessary strain degree in the whole volume of the billet.

\section{The role of the initial structure and a preliminary refinement of the alloys' structure}

As noted above, alloys in the cast condition are usually characterized by a rather coarse-grained or coarse-lamellar structure. At metallurgical plants they are normally immediately subjected to deformation processing (forging, extrusion, pressing, rolling, etc.), in order to refine the initial cast structure. For a preliminary refinement of the structure of ingots, the scheme of multiple isothermal forging can also be used.
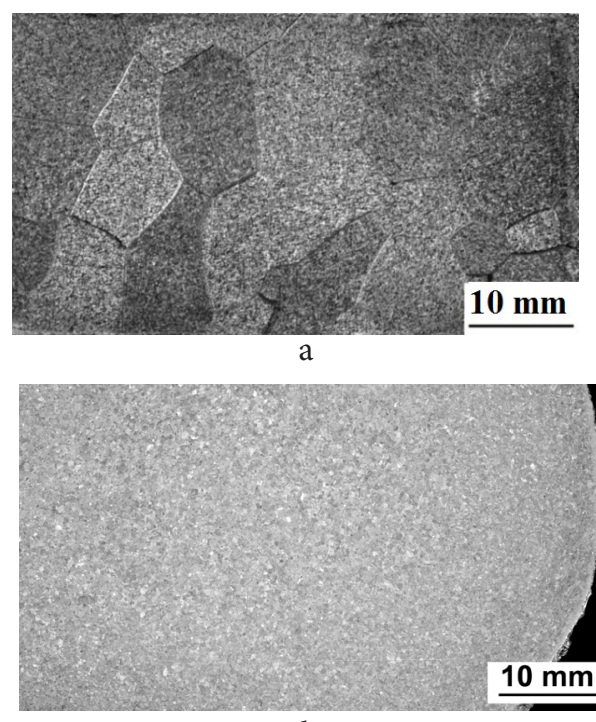

$\mathrm{b}$

Fig. 2. Macrostructure of the $\mathrm{Zr}$ alloy billet (a) in the initial cast condition and (b) after multiple isothermal forging at $T=820^{\circ} \mathrm{C}$ and subsequent annealing at $T=900^{\circ} \mathrm{C}$ for $\tau=1 \mathrm{~h}$ and water-quenching (the size of $\beta$-colonies is around $d=300 \mu \mathrm{m}$ )

As an example, let us consider a billet of a zirconium alloy E125 (Zr-2.5Nb wt.\%) which was subjected to multiple isothermal forging and subsequent annealing, aimed at a preliminary microstructure refinement. In the initial as-cast condition, this alloy had a coarse-lamellar structure (Fig.2a). Multiple isothermal forging of the $\mathrm{Zr}$ alloy billet in the twophase $\left(\alpha_{\mathrm{Zr}}+\beta_{\mathrm{zr}}\right)$ - field does not cause a development of the dynamic recrystallization process due to a low level of hot-cold work. However, the level and uniformity degree of hot-cold work turn out to be sufficient to initiate static recrystallization uniformly in the whole billet volume during subsequent annealing in the single-phase $\beta_{\mathrm{zr}}$-field. As a result, a uniform structure is formed with a relatively small size of colonies (Fig.2b). A preliminary refinement of the initial microstructure is important from the point of view of accelerating the kinetics of transformation of a lamellar structure into a globular one during subsequent thermomechanical treatment.

\section{Defining the temperature and strain- rate deformation conditions, optimal for development of dynamic recrystallization}

In order to clarify the essence of the second preliminary stage of multiple isothermal forging, let us consider as an example the microstructural changes during hot deformation of an ordered alloy based on the intermetallic compound FeAl (B2) [8]. The feature of this intermetallic alloy is that with increasing deformation temperature, at $T=750^{\circ} \mathrm{C}$ the slip direction in the alloy changes from $<111>$ to $<100\rangle$ (from superdislocations to individual dislocations). Notably, at $T=750^{\circ} \mathrm{C}$ both deformation modes are observed. The microstructure of the alloy in the cast condition was characterized by equiaxed grains with a mean size of $d=100$ $\mu \mathrm{m}$. Model cylindrical samples $(\varnothing 10 \times 15 \mathrm{~mm})$ cut out from 
the ingot were subjected to compression to a strain of $e=5 \%$ at different temperatures in the range of $T=600-900^{\circ} \mathrm{C}$. As can be seen from Fig.3, the slip direction has a significant effect on the kinetics of dynamic recrystallization. It was shown in the Ref.[8] that the absence of recrystallization at $T=600-700^{\circ} \mathrm{C}$ is associated with the properties of superdislocations whose climb is considerably hampered by the presence of the antiphase boundary band between superparticle dislocations. As a result, in the intermetallic alloy a fragmented structure forms, which, as known [9],

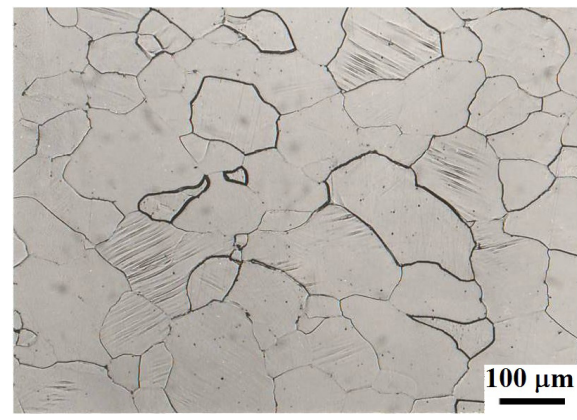

a

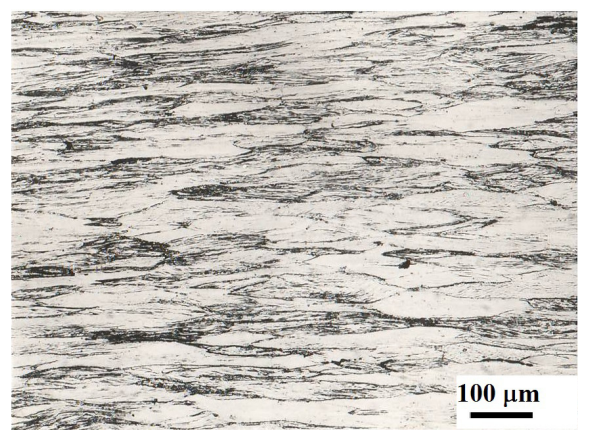

b

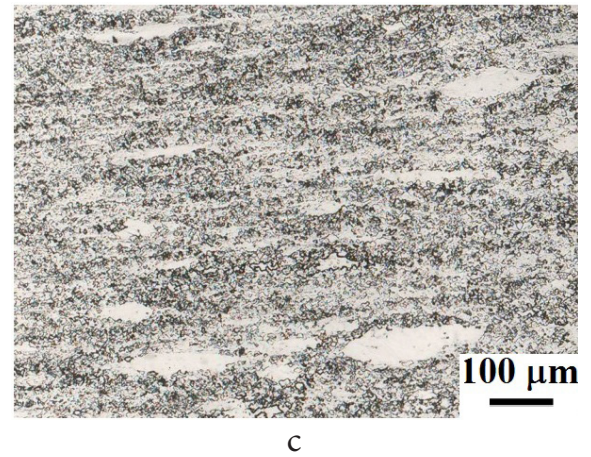

C

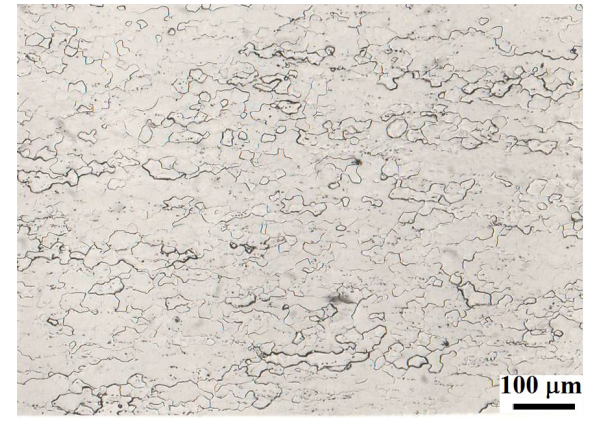

d

Fig. 3. Microstructural changes during hot deformation of an ordered alloy based on the intermetallic compound $\mathrm{FeAl}$ (B2): (a) initial state; (b) $T=700^{\circ} \mathrm{C}$; (c) $\mathrm{T}=750^{\circ} \mathrm{C}$; (d) $\mathrm{T}=900^{\circ} \mathrm{C}$; $\varepsilon=75 \%$, $\dot{\varepsilon}=77 \times 10^{-3} \mathrm{~s}^{-1}$. Vertical direction of compression. Optical microscopy. appears as a consequence of nucleation and movement of partial disclinations. Conversely, the activation of slip of individual dislocations at $T=750^{\circ} \mathrm{C}$ drastically accelerates the processes of recovery and dynamic recrystallization: new grains with typical sizes of $d=3-5 \mu \mathrm{m}$ form as a result of the interaction of individual lattice dislocations with low-angle boundaries and the conversion of the latter into high-angle grain boundaries $[10,11]$. However, as the temperature is further increased $\left(T=900^{\circ} \mathrm{C}\right)$, the acceleration of recovery impedes the mentioned conversion: there forms a mixture of low-angle and high-angle grain boundaries. Here, the build-up of misorientation and the conversion of low-angle boundaries into high-angle ones occurs as a consequence of repeated merging of some low-angle boundaries with other boundaries [12]. It is evident that the contribution of this recrystallization mechanism into the process kinetics is significantly smaller than the contribution of the above described mechanism for a lower temperature $\left(T=750^{\circ} \mathrm{C}\right)$. In the conditions of increased temperatures $\left(T=900^{\circ} \mathrm{C}\right)$, a small contribution into the recrystallization kinetics is also made by the initial grain boundaries, whose local migration facilitates the formation of new grains [13].

The specifically selected example, considered above, allows one to make several important conclusions. To develop the processing route for producing the UFG state in a certain material through deformation, it is reasonable first to perform preliminary investigations in a broad range of temperatures and strain rates of deformation processing using model samples. Selection of the deformation regime, i.e. the temperature and strain-rate conditions, has the most important significance for the process of multiple isothermal forging. «Blind» deformation processing, which is often used when applying SPD techniques, hoping for the possibility to introduce a large energy of plastic strain and for selforganization of the dislocation structure, is not appropriate from the practical standpoint.

The presented experiment illustrates that dynamic recrystallization mechanisms provide a significantly faster division of grains, rather than mechanisms related to the movement of partial disclinations leading to a formation of geometrically necessary boundaries with high misorientation angles. However, an increase in the rate of dynamic recovery, observed with increasing temperature, leads again to a deceleration of the grain division process, due to a change in the mechanism of dynamic recrystallization.

Let us consider the presented results from the point of view of the SPD principles. As the results demonstrate, dynamic recrystallization proceeds intensively only at $T>0.6 T_{\text {melt }}$. The recommendation to conduct deformation below $T<0.4 T_{\text {melt }}$ is opposite to the final goal, i.e., producing a fine-grained structure. At $T>0.6 T_{\text {melt }}$ there is no need to introduce an extraordinarily high strain energy into the material, i.e. to follow the second principle. In the conditions when dynamic recrystallization proceeds intensively, the alloy based on the intermetallic compound FeAl exhibits an enhanced deformation capacity, therefore there is no need to apply the third principle, i.e. to create a high hydrostatic pressure.

Note should be made that the presence of a close association between the deformation mechanisms of 
metals and alloys and the mechanisms and kinetics of recrystallization was established in a series of works [1416]. They have demonstrated that changes in the acting deformation mechanisms lead to changes in dynamic recrystallization mechanisms, which, in turn, determines the process kinetics. For instance, a significant influence on this triad can be made by the initial microstructure (grain size and morphology, stacking fault energy, the presence of dispersed phases). By variation of these parameters, as well as deformation regimes, favourable conditions can be ensured for development of dynamic recrystallization practically in any material, which in the first place implies the provision of multiple slip (twinning) and a certain rate of dynamic recovery.

\section{The formation of a uniform, equiaxed fine- grained structure in large-section billets}

Let us consider the formation of a uniform, equiaxed finegrained structure with a large fraction of high-angle grain boundaries without a sharp crystallographic texture in largesection billets taking the Zr alloy E125 as an example. First, a billet of this alloy was subjected to the thermomechanical treatment described above, with a view to refine the initial cast structure. Thereafter, the billet was subjected to multiple isothermal forging in the middle of the $\left(\alpha_{\mathrm{zr}}+\beta_{\mathrm{Zr}}\right)-$ phase field at $T=700^{\circ} \mathrm{C}$ and $\dot{\varepsilon}=5 \times 10^{-4}-10^{-3} \mathrm{~s}^{-1}$. This deformation regime was selected as the optimal one on a basis of preliminary studies of the dependence of the kinetics of a lamellar structure transformation into a globular one on the temperature and strain-rate deformation conditions carried out on model samples. Note should be made that at $T=700^{\circ} \mathrm{C}$ the volume fractions of the $\alpha_{\mathrm{zr}}$ and $\beta_{\mathrm{zr}}$ phases have a ratio of 86:14.

As a result of forging in the indicated optimal regime, in the $\mathrm{Zr}$ alloy billet a uniform fine-grained structure with a grain/subgrain size of $d=1.5 \mu \mathrm{m}$ is formed. The scheme of the thermomechanical treatment and the billets produced via this scheme are shown in Fig.4.

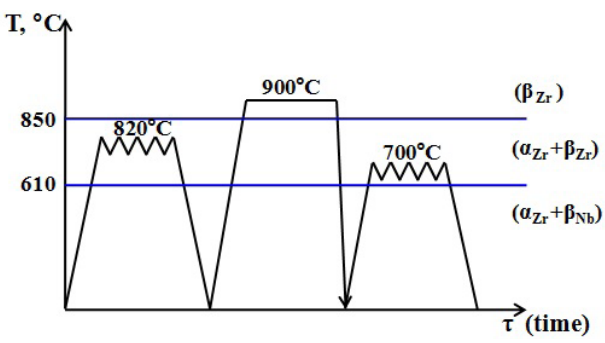

a

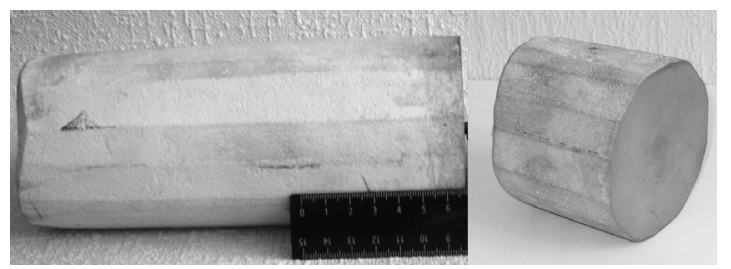

$\mathrm{b}$

Fig. 4. Scheme of (a) thermomechanical treatment and (b) billets $\varnothing 80 \mathrm{~mm}$ with a fine-grained structure $(d=1.5 \mu \mathrm{m})$ produced via this scheme.

The rods and plates produced from these billets were carefully studied in terms of the uniformity of their structure. With that aim, the macrostructures of various cross and longitudinal sections were investigated. As an example, Fig. 5 shows a plate after cutting, the macrostructure in the billet's longitudinal section and the distribution of the average HRB hardness values in that section. The uniform matte surface of all the studied billet sections indicates the uniformity and fine-graininess of their structure. In both the longitudinal and cross sections of the billet, the variations in the average hardness values are minimum that indicates on a high uniformity of the structure and mechanical properties.
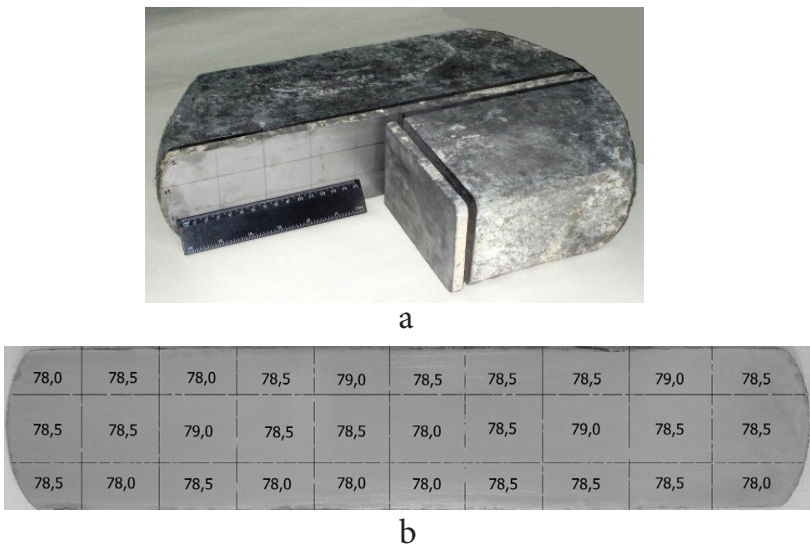

Fig. 5. Forged billet: (a) after cutting and (b) distribution of the average HRB hardness values in the cut section.

Microstructural studies in different areas of the longitudinal section of the forged billet revealed that, in spite of the macrostructural uniformity, there are regions of micro-non-uniformity observed in the microstructure of the billet: remnants of the lamellar constituent, regions with a microtexture (not shown here). The billet's texture itself is characterized by a weak and relatively uniform intensity (Fig.6). This indicates that the orientations of most grains in the material are close to random ones.

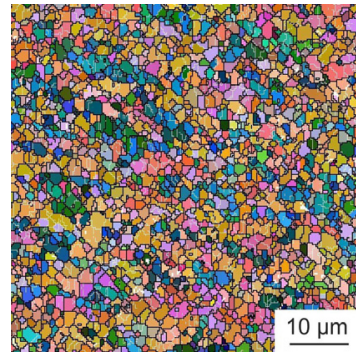

a

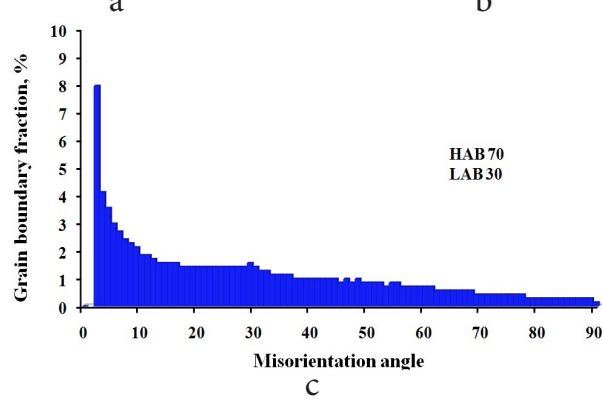

C

Fig. 6. EBSD image of the (a) Zr alloy microstructure; (b) straight pole figure (0002); (c) misorientation spectrum of $\alpha_{\mathrm{Zr}}$ - grain boundaries. 


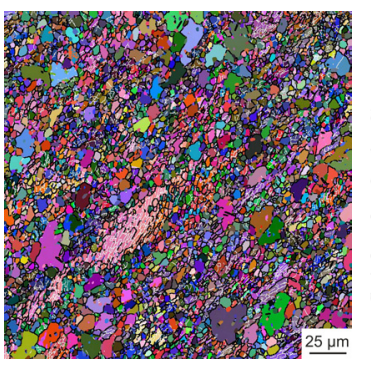

a

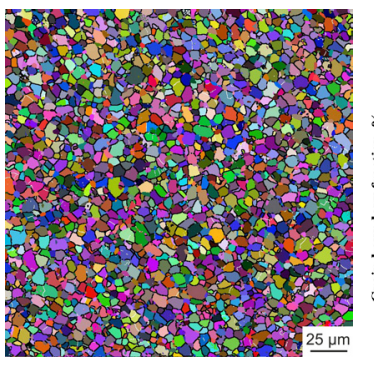

C
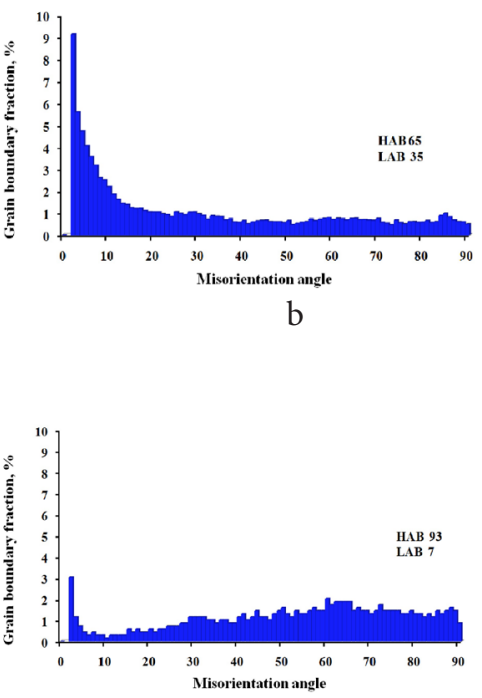

d
Fig. 7. Microstructure and misorientation spectrum of the $\alpha_{\mathrm{Zr}}$-grain boundaries (a, b) in the shoulder part of the tensile sample; (c, d) in the gauge part of the sample (after superplastic deformation at $\left.T=700^{\circ} \mathrm{C}, \varepsilon=5 \times 10^{-4} \mathrm{~s}^{-1}, \delta=500 \%\right)$.

Analyses of the EBSD images of microstructure, fine structure and the misorientation spectrum of the $\alpha_{\mathrm{zr}}$ grain boundaries in different areas of the billet's longitudinal section demonstrated that after multiple isothermal forging in the middle of the two-phase phase $\left(\alpha_{\mathrm{zr}}+\beta_{\mathrm{Zr}}\right)$ - field in the Zr alloy E125 billet a relatively uniform equiaxed fine-grained structure $(d=1.5 \mu \mathrm{m})$ with predominantly high-angle grain boundaries and a weak crystallographic texture is formed.

The degree of the microstructure uniformity in the case of multiple isothermal forging depends on the strain (the number of processing cycles and passes). Since the material is in the superplastic state, an increase in the strain leads, owing to the development of grain boundary sliding, to a more uniform distribution in the grain size and a further growth of the fraction of high-angle grain boundaries [17]. This is well illustrated by Fig.7. From the billets produced by forging at $T=700^{\circ} \mathrm{C}$ tensile samples were cut out. The sample subjected to deformation at the same temperature exhibited a superplastic elongation of $\delta=500 \%$. A comparison of the microstructure in the gauge and shoulder parts of the sample showed that the microstructure became noticeably more uniform in terms of grain size (although the grain size d grew slightly) and the fraction of high-angle grain boundaries increased.

\section{Stepwise reduction of the grain size down to the UFG scale}

Solution to the task of a stepwise reduction of the grain size down to the UFG scale is based on a stepwise decrease of the temperature of the deformation processing of the billet. It is also based on a considerable enhancement of the technological plasticity of metals and alloys owing to microstructure refinement at each preceding step. If any subsequent deformation is conducted without altering the temperature and strain-rate conditions, the material passes to the state of superplastic flow, which increases the microstructure uniformity, but does not promote its further refinement. Meanwhile, a decrease in the deformation temperature (maintaining the same strain rate) enables a further microstructure refinement. A repeated use of multiple isothermal forging at a lower temperature allows again producing a fully recrystallized, uniform microstructure with a large fraction of high-angle grain boundaries, but with a smaller size of recrystallized grains. This additional microstructure refinement leads again to the enhancement of the material's technological plasticity (transition to superplastic flow), which allows for a further decrease of the temperature of multiple isothermal forging, and so on. Thus, multiple isothermal forging with a stepwise decrease in the temperature enables grain refinement in a material down to the nano-sized range avoiding its failure during the processing. The final deformation temperature is selected on the basis of the dependence $d(T, \varepsilon)$. The number of steps, temperature differences $\Delta T_{\mathrm{i}}$ between the steps, the full temperature range $\Delta T$ between the first and the final steps, and the number of passes at the steps depend on the material type and the initial microstructure.

As an example, let us further consider the $\mathrm{Zr}$ alloy E125. For further grain size reduction, the Zr alloy billets were subjected to additional multiple isothermal forging in the $\left(\alpha_{\mathrm{Zr}}+\beta_{\mathrm{Nb}}\right)-$ phase field at $T=450^{\circ} \mathrm{C}$ (Fig.8). This processing leads to the formation of a UFG structure with a grain/subgrain size of $d=0.5 \mu \mathrm{m}$. This is accompanied by the formation of new high-angle grain boundaries, the fraction of which now exceeds $80 \%$. After the additional forging, the structure character remains the same.

The additional grain refinement, achieved at this step, leads

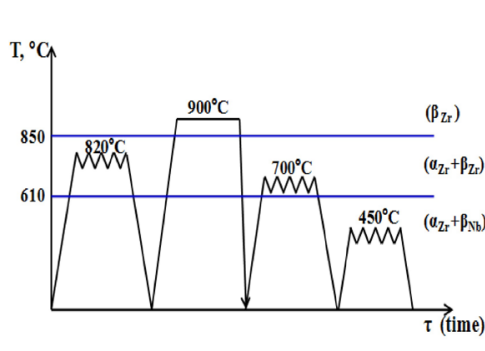

a

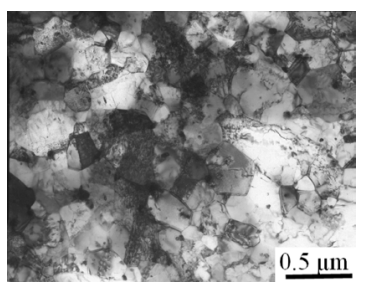

C

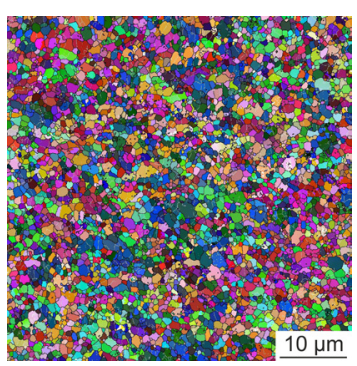

$\mathrm{b}$

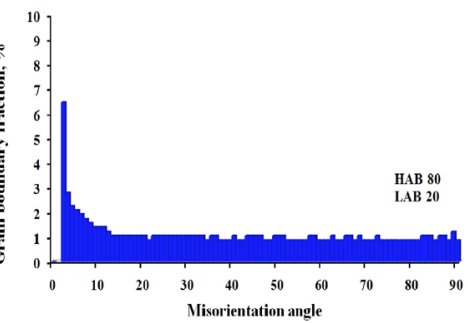

d
Fig. 8. Scheme (a) of thermomechanical treatment of the $\mathrm{Zr}$ alloy billet; (b) EBSD image of the microstructure; (c) fine structure and (d) the misorientation spectrum of $\alpha$-grain boundaries. 
to a further enhancement of the material's ductility that allows one to decrease the temperature of multiple isothermal forging down to $T=300^{\circ} \mathrm{C}$. After forging at this temperature, the grain/subgrain size reaches $d=0.2 \mu \mathrm{m}$, and the texture character and misorientation spectrum do not change significantly. Thus, multiple isothermal forging of the Zr alloy E125 billets with a stepwise temperature decrease enables their microstructure refinement down to the UFG scale, not allowing them to fracture and avoiding the formation of a sharp texture.

The key point in the above described scheme is the need to attain a uniform recrystallized microstructure with a large fraction of high-angle grain boundaries at each stage. The nonrecrystallized volumes of the materials, as well the substructure, remaining after processing at elevated temperatures, are inherited during subsequent processing at lower temperatures, since strain is localized predominantly in the fine-grained fraction. This will eventually lead to a bimodal microstructure. The strain rate at the first and subsequent stages is selected in such a way as to reduce the effect of deformation heating and, correspondingly, to ensure uniform development of recrystallization processes. At each step, as the microstructure gets refined, the material passes to the superplastic state, promoting eventually the formation of a uniform UFG structure.

The above stated principles of producing bulk semiproducts with a uniform UFG structure have been successfully applied at IMSP RAS to dozens of different metals and alloys, such as titanium and titanium-based alloys, steels, aluminum, magnesium, copper, nickel based alloys including hard-todeform nickel-based superalloys and intermetallic alloys (based on the compounds $\mathrm{TiAl}, \mathrm{Ti}_{3} \mathrm{Al}, \mathrm{Ti}_{2} \mathrm{AlNb}$ ) [18-29]. The largest and most uniform UFG semi-products have been produced from the Ti-based alloy VT6. For instance, in a rod with $\varnothing=200 \mathrm{~mm}$ and $L=300 \mathrm{~mm}$ an average grain/subgrain size of $d=0.4 \mu \mathrm{m}$ has been achieved.

\section{Conclusions}

The technique of multiple isothermal forging developed at IMSP RAS is a universal method for microstructure refinement in metals and alloys that allows for processing a uniform, in terms of the grain size, UFG structure containing predominantly high-angle grain boundaries in semiproducts with geometrical dimensions considerably larger than those which can be obtained by other techniques, for instance, by equal-channel angular pressing. The developed process, which is based on the full use of the potential of dynamic recrystallization and other thermally-activated processes, has a market potential, since it implies a minimization of the introduced strain energy and expenses for contact friction per weight unit of a UFG product and takes into account manufacture realia, because it can be easily adapted to the available pressing facilities equipped with a simple and inexpensive processing tooling.

\section{References}

1. N.A. Smirnova, V. I. Levit, V.P. Pilyugin, R. I. Kurnetsov, L.S. Davydova, R.A. Sazonova. Fiz. Met. Metalloved. 61, 1170
(1986). (in Russian)

2. N.A. Smirnova, V.I. Levit, V.P. Pilyugin, R.I. Kurnetsov, M.V. Degtyaryov. Fiz. Met. Metalloved. 62, 566 (1986). (in Russian)

3. N.A. Akhmadeev, R.Z. Valiev, V.I. Kopylov, R.R. Mulyukov. Metally. 5, 96 (1992). (in Russian)

4. R.Z. Valiev, I.V. Alexandrov. Bulk Nanostructured Metallic Materials. M., Academkniga. (2007) 398 p. (in Russian)

5. R.Z.Valiev, A.P.Zhilyaev, T.G. Langdon. Bulk Nanostructured Materials.TMS Wiley. (2014) 440 p.

6. S.V. Dobatkin, G.A. Salishchev, A.A. Kuznetsov, A.V. Reshetov, A.S. Synkov, T.N. Konkova. Fizika i Tekhnika Vysokikh Davleniy. 16(4), 23 (2006). (in Russian)

7. A. Gholinia, P.B. Prangnell, M. V. Markushev. Acta Mater. 48, 1115 (2000).

8. R. Imayev, E. Evangelista, O. Tassa, J. Stobrava. Mat. Sci. Eng. 20211(2), 128 (1995).

9. V.V. Rybin. Large Plastic Strains and Fracture of Metals. M., Metallurgiya. (1986) 224 p. (in Russian)

10. M.E. Kassner, M.E. McMahon. Met. Trans. 18A(6), 835 (1988).

11. M.E. Kassner. Met. Trans. 20A(5), 1989 (1988).

12. A.N. Belyakov, R.O. Kaibyshev. Fiz. Met. Metalloved. 78(1), 130 (1994). (in Russian)

13. G. Gottstein, L. Chang, H.F. Yung. Mat. Sci. Techn. 7, 152 (1991).

14. N.G. Zaripov, A.R. Vagapov, R.O. Kaibyshev. Fiz. Met. Metalloved. 63, 774 (1987). (in Russian)

15. R. O. Kaibyshev. Proc. Int. Conf. on Recrystallization in Met. Mater. Australia. 2, 855 (1990).

16. R.O. Kaibyshev, O.Sh. Sitdikov. Proceedings of the USSR Academy of Sciences. 321, 306 (1991). (in Russian)

17. R.O. Kaibyshev. Superplasticity of Commercial Alloys. M., Metallurgiya. (1984) 276 p. (in Russian)

18. R.R. Mulyukov. Rossiiskie Nanotekhnologii. 2(7-8), 38 (2007). (in Russian)

19. R.R. Mulyukov, R.M. Imayev, A. A. Nazarov. J. Mater. Sci. 43, 7257 (2008).

20. O.R. Valiakhmetov, R.M. Galeyev, G.A. Salishchev. Fiz. Met. Metalloved. 10, 204 (1990).

21. R.M. Imayev, V.M. Imayev. Scripta Met. 25, 2041 (1991).

22. G. A. Salishchev, O.R. Valiakhmetov, R.M. Galeyev. J. Mater. Sci. 28, 2898 (1993).

23. R.M. Imayev, V.M. Imayev, G.A. Salishchev. J. Mater. Sci. 27, 4465 (1992).

24. S.V. Zherebtsov, G.A. Salishchev, R.M. Galeyev, O.R. Valiakhmetov, S. Yu. Mironov, S. L. Semiatin. Scr. Mater. 51, 1147 (2004).

25. G.A. Salishchev, O.R. Valiakhmetov, R.M. Galeyev, S.P. Malysheva. Metally. 4, 86 (1996). (in Russian)

26. G.A. Salishchev, M.A. Murzinova, S.V. Zherebtsov, R.M. Galeyev, O.R. Valiakhmetov. TMS 131st Annual Meeting \& Exhibition, International Symposium on Ultrafine Grained Materials II. Seattle, Washington, USA, February 17-21, 2002. TMS, Warrendale, PA. (2002) 113 p.

27. F.Z. Utyashev, R. O. Kaibyshev., V.A. Valitov. European Patent EP 0.909.339 B1. 2001.

28. R.M. Imayev, G.A. Salishchev, O.N. Senkov, V.M. Imayev, N.K. Gabdullin, M.R. Shagiev, A.V. Kuznetsov, F.H. Froes. Mat. Sci. Eng. 300, 263 (2001).

29. R.M. Imayev, N.K. Gabdullin, G.A. Salishchev, O.N. Senkov, V.M. Imayev, F.H. Froes. Acta Mater. 47, 1809 (1999). 